\title{
Solitary Eccrine Syringofibroadenoma (or Eccrine Syringofibroadenomatous Hyperplasia?) and Diabetic Polyneuropathy
}

\begin{tabular}{|c|c|}
\hline C. & Gambini $^{\mathrm{a}}$ \\
\hline $\mathrm{F}$. & Rongioletti $^{b}$ \\
\hline M.T. & Semino $^{b}$ \\
\hline A. & Rebora $^{b}$ \\
\hline
\end{tabular}

${ }^{a}$ Division of Pathology, G. Gaslini Institute, and ${ }^{\mathrm{b}}$ Department of Dermatology, University of Genoa, Italy

\section{Key Words}

Eccrine syringofibroadenoma

Diabetes

Polyneuropathy

Abstract

A 70-year-old diabetic woman with sensory polyneuropathy presented with osteonecrosis of the toes and a plaquelike lesion on the dorsum of the ipsilateral foot. Histological diagnosis of eccrine syringofibroadenoma (ES) was made. A review of the literature reveals several cases of solitary ES of the foot in diabetic patients with peripheral neuropathy. This variant of ES seems to be an eccrine sweat duct hyperplasia during the restoration of skin structures damaged by traumas in a situation of peripheral neuropathy. Diabetes and polyneuropathy should be searched for in patients with ES, particularly in acral locations.

Dr. Franco Rongioletti, Istituto di Dermatologia, Università di Genova, Viale Benedetto XV 7, I-16132 Genova (Italy) Eccrine syringofibroadenoma (ES) is a distinctive histological entity [1] with polymorphous clinical presentation [2]. Mainly because of such a polymorphism, its noso-graphy is controversial.

The patient we describe provides some clues to discuss the histogenesis and noso-graphy of ES. Case Report

A 70-year-old woman with diabetes mel-litus had had partial osteonecrosis of her toes years before a lesion developed on the dor-sum of her foot which slowly enlarged. There was no family history of similar lesions and no evidence of other tumors nor of ectoder-mal dysplasia. The patient complained of prickling and burning sensations of her legs and feet.

On physical examination, a flesh-colored, verrucous, $8 \times 20 \mathrm{~cm}$ wide plaque was seen on the dorsum of her right foot extending to the lateral aspect (fig. 1). A chronic ulcer of the sole was also noted. Neurological examination of the lower limbs showed a decreased or absent sensation for touch, pinprick and heat-cold due to a diabetic sensory polyneuropathy, confirmed by nerve conduction studies.

The whole lesion was surgically removed. Histopathology showed an epithelial proliferation with thin, anastomosing strands of small cuboidal cells extending into the underlying dermis (fig. 2). The epithelial cords contained cystic spaces and ductal structures lined by a single layer of flattened cells and by a 
distinct cuticle (fig. 3). The stroma showed an increased vascularity and fibrosis with an inflammatory infiltrate of few lymphocytes, plasmacytes and an exceedingly high number of mast cells, confirmed by to-luidine blue stain. The luminal ductal cells expressed carcinoembryonic antigen.

Discussion

ES was described by Mascarò in 1963 in two 63-year-old patients. They had a solitary nodule on the upper lip and a solitary plaque on the leg, respectively [1]. Both lesions showed a proliferation of anastomosing cords and strands of epithelial cells, ductal aspects within the latter and a fibrovascular inflammatory stroma. About 31 cases have been reported since $[2,3]$. Although all these cases have the same peculiar histological pattern, they are clinically polymorphous. They range from a solitary papule, nodule or plaque to multiple lesions with a linear and symmetric arrangement or with a palmoplantar distribution. Even a mucous presentation has been described [4]. The lesions may also involve sites as different as the face, back, abdomen or upper and lower

extremities. ES occurs preferentially in patients between the 5th and 8th decades and evolves within 6 months to 20 years.

The present classification includes solitary ES, multiple ES, multiple ES with hy-drotic ectodermal dysplasia and ES associated with other tumors [5]. Nosography is controversial, however. Solitary lesions of short duration have been considered a neoplasm while multiple symmetric, linear, long-standing lesions have been regarded as hamartoma [6,7]. Finally, ES has also been considered a nonspecific histological pattern of proliferation reactive to various skin disorders $[8,9]$.

Accordingly, the solitary plaque-like lesion of a relatively short duration in our patient should be considered a neoplasm. The same clinical presentation was found by Hurt et al. [5] and Sueki et al. [10]. Their 3 patients were middle-aged diabetics who had had osteonecrosis and partial amputation of toes years before they saw a plaque-like ES developing on their dorsal foot. Altogether, the association of ES with insulin-dependent diabetes has been reported in 5 out of 31 cases in the literature $[4,5,10,11$, present case]. All patients had their foot involved. A peripheral neuropathy was also observed in another patient affected by lepromatous leprosy [12]. He had a nodular lesion with histological features of ES at the edge of an ulcer in an anesthetic foot [12]. The plaque-like solitary ES of

\section{KAKGER}

E-Mail karger <3/8karger.ch Fax+4161306 1234 http://www.karger.ch

(C) 1996 S.KargerAG, Basel

1018-8665/96/1931-0068\$10.00/0

$\mathrm{y}^{3 / 8} / \mathrm{s}^{3 / 3} / 8$ 
Hurt MA, Igra-Serfaty H, Stevens CS: Eccrine syringofibroadenoma (Mascarò): An acrosyringeal hamartoma. Arch Dermatol 1990;26: 945-949.

Hara K, Mizuno E, Nitta Y, Ikeya T: Acro-syringeal adenomatosis (eccrine syringofibroadenoma of Mascarò): A case report and review of the literature. Am J Dermatopathol 1992;14:328-339. Abenoza P, Ackermann AB: Neoplasms with Eccrine Differentiation, ed 5. Philadelphia, Febiger, 1990, pp 275-284. Nomura K, Kogawa J, Hashimoto 1, Katabira Y: Eccrine syringofibroadenomatous hyperplasia in a patient with bullous pemphigoid: A case report and review of the literature. Der-matologica 1991;182:59-62. Mehregan AH: Proliferation of sweat ducts in certain diseases of the skin. Am J Dermatopathol 1981;3:27-31.

Sueki H, Miller SS, Dzubow LM, Murphy GF: Eccrine syringofibroadenoma (Mascarò): An ultrastructural study. J Cutan Pathol 1992; 19: 232-239.

Lui H, Stewart WD, English SC, Wood WS: Eccrine syringofibroadenomatosis: A clinical and histological study and review of the literature. J Am Acad Dermatol 1992;26:805-813. Mehregan AH, Marufi M, Medenica M: Eccrine syringofibroadenoma (Mascarò). J Am Acad Dermatol 1985;13:433-436. Persinger MA, Lepage P, Simard JP, Parker GH: Mast cell numbers in incisional wounds in rat skin as a function of distance, time and treatment. Br J Dermatol 1983;108:179-183.

Eccrine Syringofibroadenoma

Dermatology 1996:193:68-69

69 